\title{
A meta-analysis of the safety and efficacy of bosentan therapy combined with prostacyclin analogues or phosphodiesterase type-5 inhibitors for pulmonary arterial hypertension
}

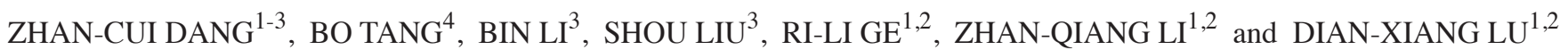 \\ ${ }^{1}$ Research Center for High Altitude Medicine, Qinghai University; ${ }^{2}$ Key Laboratory of Application and Foundation for \\ High Altitude Medicine Research in Qinghai Province; ${ }^{3}$ Public Health Department, Medical College, Qinghai University; \\ ${ }^{4}$ Department of Orthopaedics, The First People's Hospital of Xining City in Qinghai Province, Xining, Qinghai 810000, P.R. China
}

Received December 4, 2018; Accepted August 21, 2019

DOI: $10.3892 /$ etm.2019.8142

\begin{abstract}
Bosentan is an effective drug for the treatment of pulmonary arterial hypertension (PAH). The aim of the present meta-analysis was to examine the evidence concerning the efficacy and safety of bosentan therapy combined with prostacyclin analogues or phosphodiesterase type 5 (PDE-5) inhibitors for treating PAH. Eligible published studies were collected from Embase, PubMed, The Cochrane Library and the www. clinicaltrials.gov website. Heterogeneity was assessed using the Cochran Q-statistic test. Results were presented as risk ratios or mean differences with $95 \%$ confidence intervals (CI). A total of five studies, comprising 310 patients were included for analysis. No significant improvements in six-minute walk distance (6MWD; mean difference, $16.43 \mathrm{~m}$ ), clinical worsening (risk ratio, 0.54) and the World Health Organization functional classification (class I: risk ratio, 1.17; class II: risk ratio, 1.18) were observed in patients treated with bosentan in combination with prostacyclin analogues or PDE-5 inhibitors. However, a significant reduction in the mean pulmonary artery pressure (mPAP; 95\% CI: -17.06, -6.83; $\mathrm{P}<0.0001)$ following bosentan combination therapy was observed. Comparisons of adverse event rates in the bosentan combination therapy (55.6\%) and monotherapy (51.8\%) suggested that there is no reduction in adverse events (risk ratio, 1.10). The results indicated that bosentan combined with prostacyclin analogues or
\end{abstract}

Correspondence to: Dr Zhan-Qiang Li or Dr Dian-Xiang Lu, Research Center for High Altitude Medicine, Qinghai University, 16 Kunlun Road, Xining, Qinghai 810001, P.R. China

E-mail: zhanqiang_li@163.com

E-mail: ludiaxiang@qhu.edu.cn

Abbreviations: 6MWD, six-minute walk distance; ERA, endothelin receptor antagonist; mPAP, mean pulmonary artery pressure; $\mathrm{PAH}$, pulmonary arterial hypertension; PDE-5, phosphodiesterase type 5

Key words: meta-analysis, bosentan combination therapy, prostacyclin analogues, phosphodiesterase type 5 inhibitors, pulmonary arterial hypertension
PDE-5 inhibitors may not improve 6MWD, cardiac function, clinical worsening and adverse events. However, bosentan combined with prostacyclin analogues or PDE-5 inhibitor therapy was able to significantly reduce mPAP compared with the effect of bosentan monotherapy.

\section{Introduction}

Pulmonary arterial hypertension $(\mathrm{PAH})$ is a progressive disease associated with a massive increase in pulmonary vascular resistance and pulmonary artery pressure (PAP). PAH is a rare disease with an incidence of approximately 2.4-7.6 cases per million (1), which may lead to fatal right heart failure in the absence of appropriate treatment. The pathogenesis of PAH has not been fully elucidated; however, dysfunction of three metabolic/physiological pathways, including the endothelin pathway, the prostacyclin pathway and the nitric oxide pathway, have been attributed to the pathogenesis of PAH $(2,3)$. Targeting of these pathways had been rationally exploited for the discovery of chemotherapeutics against PAH. For example, prostacyclin analogues, phosphodiesterase type 5 (PDE-5) inhibitors and endothelin receptor antagonists (ERAs) are drugs that are commonly used for the treatment of PAH (4). These drugs relieve symptoms, raise exercise capacity and improve hemodynamics. However, the efficacies of these commonly used drugs in delaying the progression of the disease are limited. Owing to these limitations, the current treatment options for PAH are not satisfactory. Combination therapies exist, where two or three drugs aimed at different pathways, such as ERAs, prostacyclin analogues and PDE-5 inhibitors are simultaneously used (5). Previous studies had indicated that combination therapy significantly improved activity tolerance, hemodynamic parameters, clinical deterioration time and quality of life for patients with PAH (6-8). Results from a previous meta-analysis suggest that combination therapies only offered a modest increase in exercise ability (9). The evidence to support these treatment options is limited. Bosentan, an ERA, serves a crucial role in proliferation inhibition, improvement of endothelial function and expansion of pulmonary vessels (10). ERA treatment significantly improved the activity tolerance and exercise capacity of PAH 
patients as well as prolonging the survival time (11); however, PAH remains a progressive disease with a high mortality rate (12-15). The mortality rate of pulmonary hypertension in the United States was about 4.5-12.3/10 million in 2015 (16). In order to achieve long-term efficacy, combined therapy has been widely used in clinical practice. However, only a few randomized controlled trials are available regarding the efficacy and safety of combining bosentan with prostacyclin analogues or PDE-5 inhibitors, and there is limited evidence to support the superior effects of bosentan combination therapy over monotherapy (17). The present meta-analysis focused on providing an improved analysis of bosentan combination for PAH treatment, and laying a theoretical foundation for the development of other treatment strategies in the future. Bosentan was the first oral PAH targeted drug in 2002 (18). Subsequently, a number of multi-center, randomized controlled clinical trials have been published to confirm its efficacy in controlling pulmonary hypertension $(19,20)$. Bosentan was approved in China for the treatment of PAH in 2006 and was permitted for use as class I drug in 2015, according to European Society of Cardiology-European Respiratory Society Guidelines on Pulmonary Hypertension (21). The evidence-based medicine of bosentan combined with prostacyclin analogues or PDE-5 inhibitors is lacking. Therefore, it is necessary to conduct meta-analyses of randomized controlled trials to evaluate the effects of bosentan combined with prostacyclin analogues or PDE-5 inhibitors for the treatment of PAH. The present meta-analysis may provide evidence of the efficacy and safety of bosentan therapy combined with prostacyclin analogues or PDE-5 inhibitors.

\section{Materials and methods}

Study inclusion and exclusion criteria. The following criteria was used for selecting previous studies to analyse: i) Only randomized controlled trials (RCT) that combined bosentan with prostacyclin analogues or PDE-5 inhibitors for the treatment of PAH were included; ii) studies in which the control group was treated with bosentan or placebo were included (bosentan monotherapy), and follow-up time in the study was $\geq 12$ weeks.; iii) studies of the bosentan treatment within 3 months prior to randomization were included. Efficacy indicator of primary endpoint was indicated as six-minute walk distance (6MWD), and adverse events were examined to evaluate safety.

Literature search. RCT of bosentan combination therapy vs. bosentan monotherapy for treatment of PAH were searched from PubMed (www.ncbi. nlm.nih.gov/pubmed), Embase (www.embase.com), and the Cochrane library (www.cochrane library. com). The following keywords were used for searching the relevant trial studies included in this meta-analysis: 'Phosphodiesterase type 5 inhibitor' or 'PDE-5 inhibitor' or 'sildenafil' or 'tadalafil' or 'vardenafil' or 'prostacyclin analogs' or 'epoprostenol' or 'iloprost' or 'treprostinil' paired with 'pulmonary arterial hypertension' or 'PAH' and 'bosentan'.

Quality assessment. The selected studies were also assessed for the quality of trials using the Cochrane Collaboration recommended tool for assessing risk of bias (22). This tool included the domains of selection bias (random sequence generation and allocation concealment), performance bias (blinding of participants and personnel), detection bias (blinding of outcome assessment), attrition bias (incomplete outcome data), reporting bias (selective reporting) and other sources of bias. The 'risk of bias' assessment tool was used to further review bias among individual studies (22).

Statistical analysis. Results are represented as risk ratios for dichotomous data and mean differences for continuous data with $95 \%$ confidence intervals (CI). Statistical heterogeneity across studies was tested using Cochran's Q test. The fixed effects model was selected for analysis when no significant heterogeneity between the studies was found $\left(\mathrm{P}>0.10 ; \mathrm{I}^{2}\right.$ $\leq 50 \%$ ). Alternatively, the random effects model was used in case heterogeneity among studies. The RevMan software package (version 5.2; Cochrane) was used for all statistical analyses.

\section{Results}

Study characteristics. In the present meta-analysis, one RCT (PHIRST-1: Tadalafil in the Treatment of Pulmonary Arterial Hypertension) was reported twice $(23,24)$. The trials consisted of patients with congenital heart disease-associated PAH (25) and Eisenmenger's syndrome (26). The subjects of six studies were treated with ERA or PDE-5 inhibitor as background treatment (27-32); therefore, these were excluded from the analysis. Overall, a total of 310 subjects in 5 RCTs were included in this analysis (Fig. 1 and Table I).

Data quality. The quality of the five studies was assessed and the risk of bias was estimated by Cochrane Collaboration's tool. The results were shown in Fig. 2. The majority of the included studies had a low risk of bias according to the following criteria: Selection bias, performance bias, detection bias, attrition bias, reporting bias and other sources of bias.

Meta-analysis results. 6MWD was used as an indicator of exercise ability in all the five trials included in the present study. Compared with bosentan monotherapy, four of the five studies in bosentan combination therapy reported a significant improvement in walking distance (Fig. 3). The mean difference of 6MWD in bosentan combination therapy was $16.43 \mathrm{~m}$ (95\% CI: -4.91, 37.76), but there was no statistical significance between bosentan combination and bosentan monotherapy $(\mathrm{P}=0.13)$. No significant heterogeneity $\left(\mathrm{I}^{2}=0 \% ; \mathrm{P}=0.81\right)$ was detected in bosentan combination therapy compared with bosentan monotherapy.

Cardiac functional improvement was also one of the efficacy indicators of this meta-analysis. The New York Heart Association (NYHA) and the World Health Organization (WHO) functional classification systems were used to identify functional impairment in PAH. McLaughlin et al (33) and Hoeper et al (34) performed their studies using the NYHA functional classification, the remaining three studies were performed using the WHO functional classification $(23,35,36)$. After meta-analysis, the result showed that there was significant heterogeneity $\left(\mathrm{I}^{2}=73 \% ; \mathrm{P}=0.02\right)$ in WHO functional class 
Table I. Study characteristics.

\begin{tabular}{|c|c|c|c|c|c|c|c|c|}
\hline Author, year & Study & $\mathrm{n}$ & $\begin{array}{c}\text { Sex } \\
\text { (male/female) }\end{array}$ & MT & CT & $\begin{array}{l}\text { Follow-up } \\
\text { (weeks) }\end{array}$ & $\begin{array}{l}\text { Primary } \\
\text { endpoint }\end{array}$ & (Refs.) \\
\hline $\begin{array}{l}\text { McLaughlin } \\
\text { et al, } 2006\end{array}$ & STEP & 67 & $14 / 53$ & $\begin{array}{l}\text { Placebo + } \\
\text { bosentan }\end{array}$ & $\begin{array}{l}\text { Bosentan + } \\
\text { Iloprost (5 ug) }\end{array}$ & 12 & 6MWD & (33) \\
\hline Hoeper et al, 2006 & COMBI & 40 & $9 / 31$ & Bosentan & $\begin{array}{l}\text { Bosentan + } \\
\text { Iloprost (5 ug) }\end{array}$ & 12 & 6MWD & (34) \\
\hline Barst et al, 2011 & PHIRST & 87 & $19 / 68$ & $\begin{array}{l}\text { Placebo + } \\
\text { bosentan }\end{array}$ & $\begin{array}{l}\text { Bosentan }+ \\
\text { tadafil }(40 \mathrm{mg})\end{array}$ & 16 & 6MWD & (23) \\
\hline Han et al, 2017 & $\mathrm{BIPH}$ & 15 & $5 / 10$ & Bosentan & $\begin{array}{l}\text { Bosentan + } \\
\text { Iloprost (10 ug) }\end{array}$ & 12 & 6MWD & $(35)$ \\
\hline Vizza et al, 2017 & & 103 & $25 / 79$ & Bosentan & $\begin{array}{l}\text { Bosentan }+ \\
\text { Sildenafil (20 mg) }\end{array}$ & 12 & 6MWD & (36) \\
\hline
\end{tabular}

6MWD, 6-min walk distance; BIPH, bosentan with iloprost in the treatment of pulmonary hypertension patients; COMBI, combination therapy of bosentan and aerosolised iloprost in idiopathic pulmonary arterial hypertension; CT, bosentan combination therapy; MT, bosentan monotherapy; PHIRST, pulmonary arterial hypertension and response to tadalafil; STEP, safety and pilot efficacy trial in combination with bosentan for evaluation in pulmonary arterial hypertension.

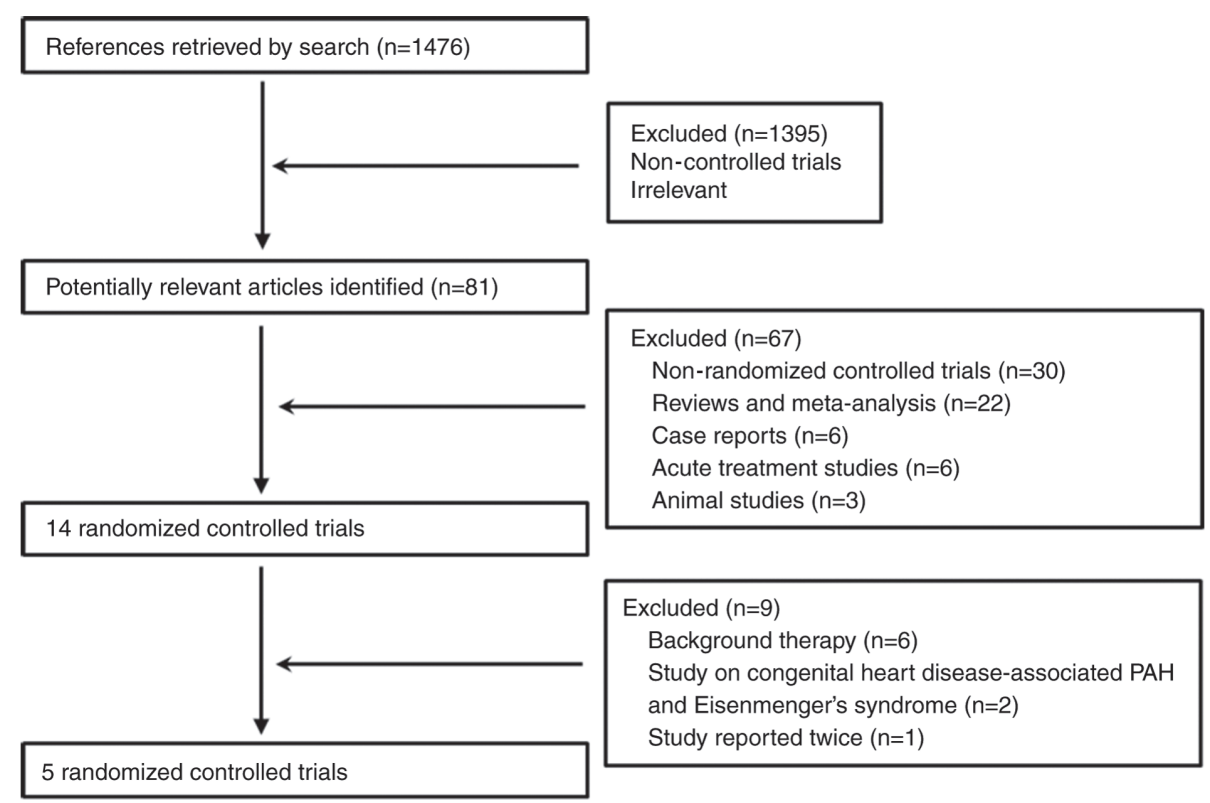

Figure 1. Flow diagram for the studies included in the meta-analysis concerning the therapy effect of bosentan combined with either prostacyclin analogues or phosphodiesterase type 5 inhibitors in PAH. PAH, pulmonary arterial hypertension.

improvement I between bosentan combination therapy and bosentan monotherapy (Fig. 4). The random effects model was used for the analysis. Functional class improvement I from baseline to endpoint of study was indicated to be $18 \%(18 / 100)$ in bosentan combination therapy and $17 \%(18 / 105)$ in bosentan monotherapy (Fig. 4A). The WHO functional class improvement II from baseline to endpoint of study was $4 \%(4 / 100)$ in bosentan combination therapy and $2.9 \%(3 / 105)$ in bosentan monotherapy, without significant heterogeneity $\left(\mathrm{I}^{2}=0 \%\right.$; $\mathrm{P}=0.44$ ) (Fig. 4B). Therefore, functional class improvements I and II exhibited no significant difference between the bosentan combination and monotherapy groups $(\mathrm{P}>0.05)$.

Two of the five trial studies reported the effects of bosentan combination therapy on mean PAP (mPAP; Fig. 5) $(33,35)$.
The difference of mPAP demonstrated an average of only 11.95 mmHg (95\% CI: -17.06, -6.83; P<0.00001) between bosentan combination therapy and monotherapy, and there was no heterogeneity between the groups $\left(\mathrm{I}^{2}=6 \%\right.$; $\left.\mathrm{P}=0.30\right)$. These data suggested that combination therapy may significantly reduce mPAP.

One study did not include any data of clinical worsening (35) The clinical worsening rate in combination therapy was $5.5 \%(8 / 145)$ compared with that of monotherapy of $10.5 \%(16 / 152)$. The heterogeneity between the groups was found to be non-significant $\left(\mathrm{I}^{2}=13 \% ; \mathrm{P}=0.33\right)$. Clinical worsening incidence in the combination therapy was below that of monotherapy (risk ratio, 0.54 ; $95 \%$ CI: $0.25,1.20$ ), but without statistical significance ( $\mathrm{P}=0.13$; Fig. 6). 

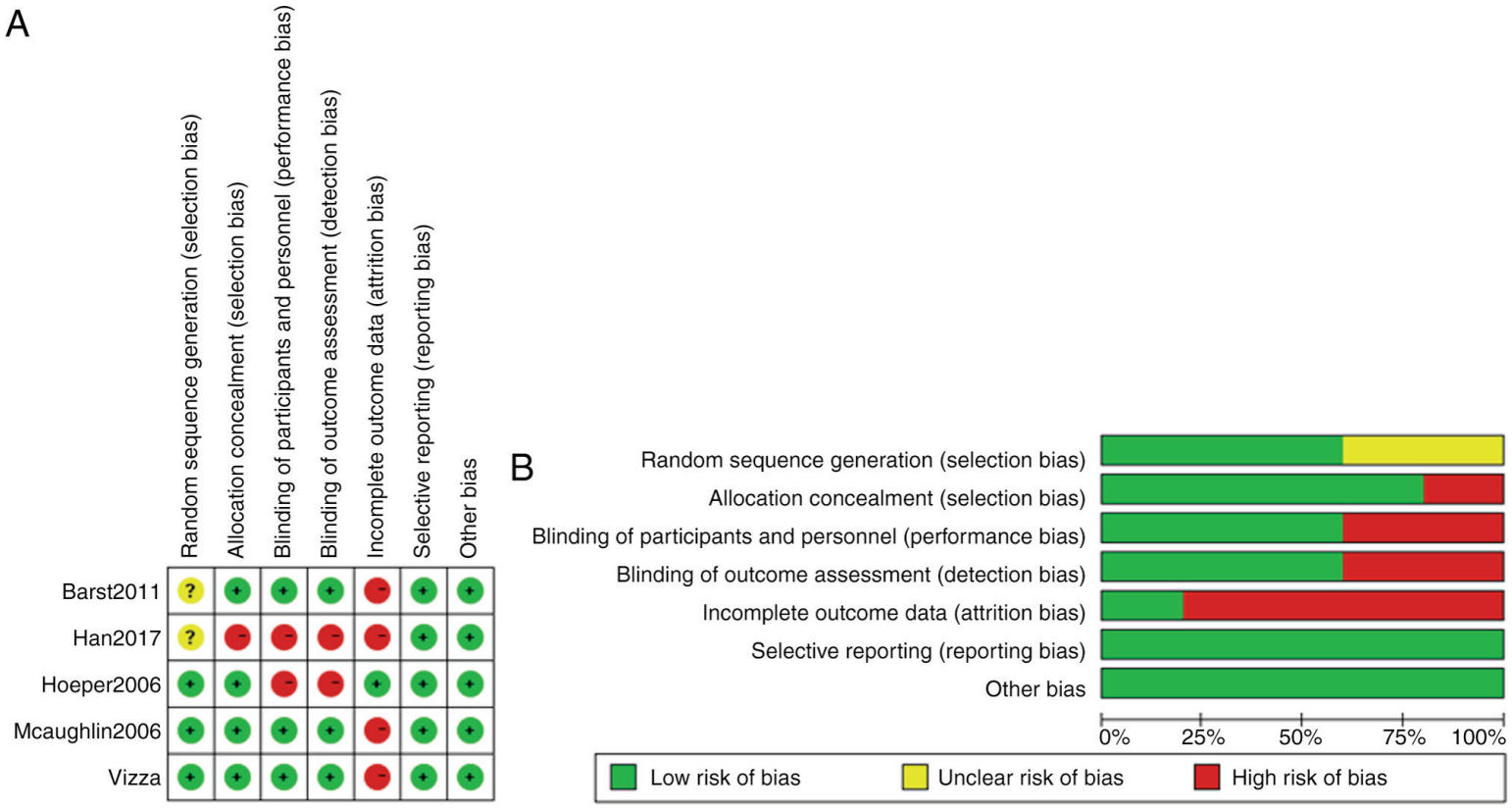

Figure 2. Risk of bias summary. (A) Risk of bias for each included RCT, representing low risk of bias (+), high risk of bias (-), and unclear risk of bias (?). (B) Bar chart comparing percentage risk of bias for each included RCT. Green, low risk of bias high; red, risk of bias; yellow, unclear risk of bias. RCT, randomized controlled trial.

\begin{tabular}{|c|c|c|c|c|c|c|c|c|c|c|c|c|}
\hline \multirow[b]{2}{*}{ Study or Subgroup } & \multicolumn{3}{|c|}{$\mathrm{CT}$} & \multicolumn{2}{|c|}{ MT } & \multirow[b]{2}{*}{ Total } & \multirow[b]{2}{*}{ Weight } & Mean difference & \multirow{2}{*}{\multicolumn{2}{|c|}{$\begin{array}{l}\text { Mean difference } \\
\text { IV, Fixed, } 95 \% \mathrm{Cl}\end{array}$}} & & \\
\hline & Mean & SD & Total & Mean & SD & & & IV, Fixed, $95 \% \mathrm{Cl}$ & & & & \\
\hline Barst2011 & 401.1 & 95.3 & 42 & 367.3 & 104.9 & 45 & $25.7 \%$ & $33.80[-8.27,75.87]$ & & & & \\
\hline Han2017 & 411.7 & 126.5 & 8 & 385.3 & 111.9 & 7 & $3.1 \%$ & $26.40[-94.25,147.05]$ & & & & \\
\hline Hoeper2006 & 309 & 124 & 19 & 297 & 94 & 21 & $9.6 \%$ & $12.00[-56.74,80.74]$ & & & & \\
\hline Mcaughlin2006 & 367 & 84 & 32 & 343 & 99 & 33 & $22.9 \%$ & $24.00[-20.59,68.59]$ & & & & \\
\hline Vizza & 368.48 & 96.3 & 50 & 367.8 & 80.1 & 53 & $38.6 \%$ & $0.68[-33.64,35.00]$ & & & & \\
\hline Total $(95 \% \mathrm{Cl})$ & & & 151 & & & 159 & $100.0 \%$ & $16.43[-4.91,37.76]$ & & & & \\
\hline \multicolumn{5}{|c|}{$\begin{array}{l}\text { Heterogeneity: } \mathrm{Chi}^{2}=1.62, \mathrm{df}=4(\mathrm{P}=0.81) ; \mathrm{l}^{2}=0 \% \\
\text { Test for overall effect: } Z=1.51 \quad(P=0.13)\end{array}$} & & & & & $\begin{array}{l}-50 \\
\text { Favours [MT] }\end{array}$ & ]$^{0}$ Favours & $\begin{array}{c}50 \\
{[\mathrm{CT}]}\end{array}$ & 100 \\
\hline
\end{tabular}

Figure 3. Effect of bosentan combined with prostacyclin analogues or phosphodiesterase type 5 inhibitors vs. bosentan monotherapy on $6 \mathrm{MWD}$. There was no significant heterogeneity ( $\mathrm{I} 2=0 \% ; \mathrm{P}=0.81)$ The mean difference of $6 \mathrm{MWD}$ was not significant between bosentan combination and bosentan monotherapy ( $\mathrm{P}=0.13$ ). 6MWD, six-minute walking distance; $\mathrm{CI}$, confidence intervals; $\mathrm{CT}$, combination therapy; IV, inverse variance; MT, monotherapy.

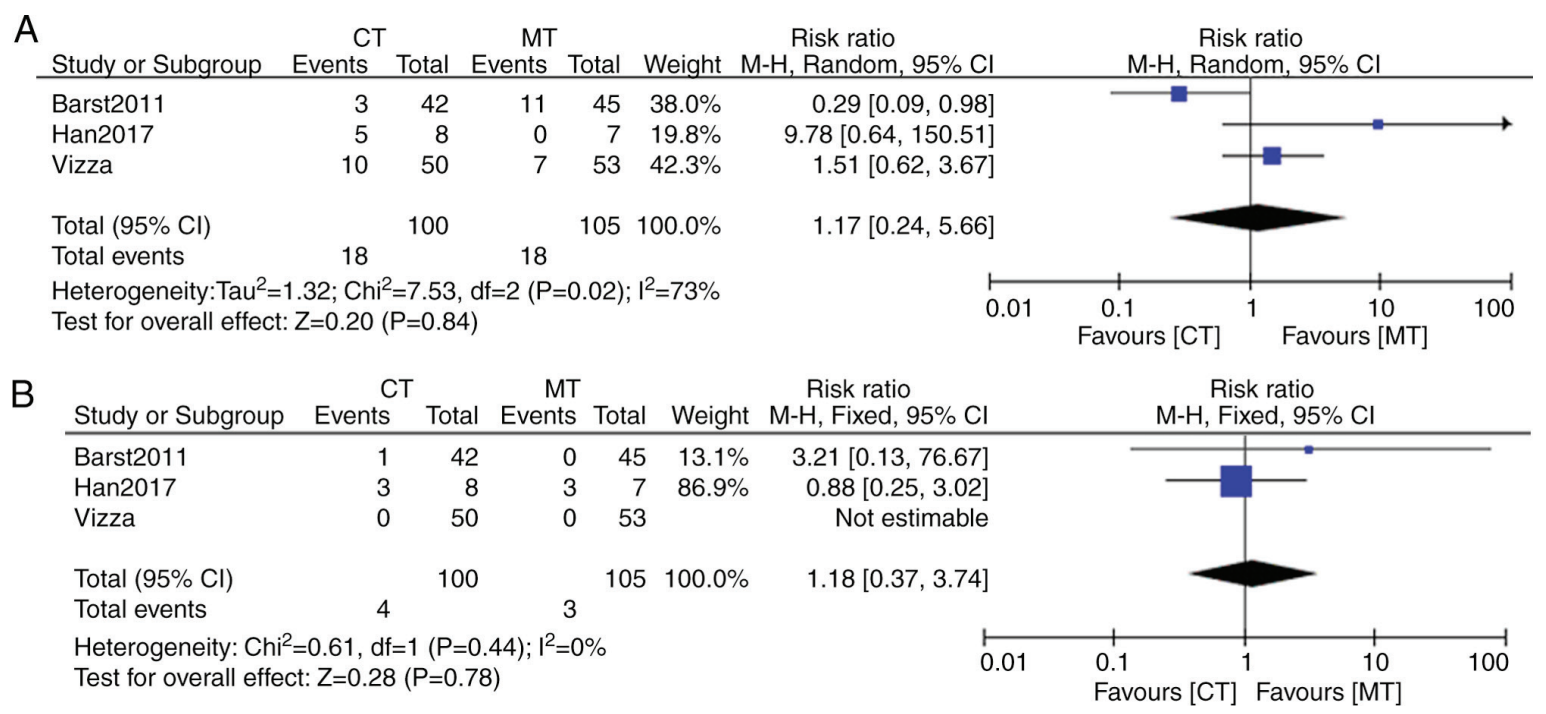

Figure 4. Effect of bosentan combined with prostacyclin analogues or phosphodiesterase type 5 inhibitors vs. bosentan monotherapy on WHO functional class improvement. (A) WHO functional class improvement I and (B) WHO functional class improvement II. Functional class improvement I and II from baseline to endpoint of study were not significantly different in bosentan monotherapy and bosentan combination therapy (P>0.05). CI, confidence intervals; CT, combination therapy; M-H, Mantel-Haenszel; MT, monotherapy; WHO, World Health Organization. 


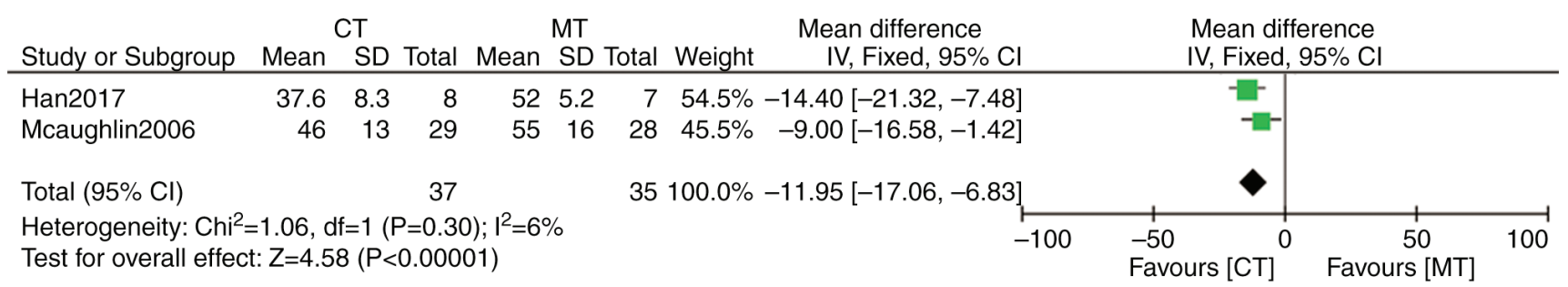

Figure 5. Effect of bosentan combined with prostacyclin analogues or phosphodiesterase type 5 inhibitors vs. bosentan monotherapy on mean pulmonary artery pressure. Compared with bosentan monotherapy, combination therapy may significantly reduce mPAP $(\mathrm{P}<0.05)$. CI, confidence intervals; CT, combination therapy; IV, inverse variance; MT, monotherapy; SD, standard deviation; mPAP, mean pulmonary artery pressure.

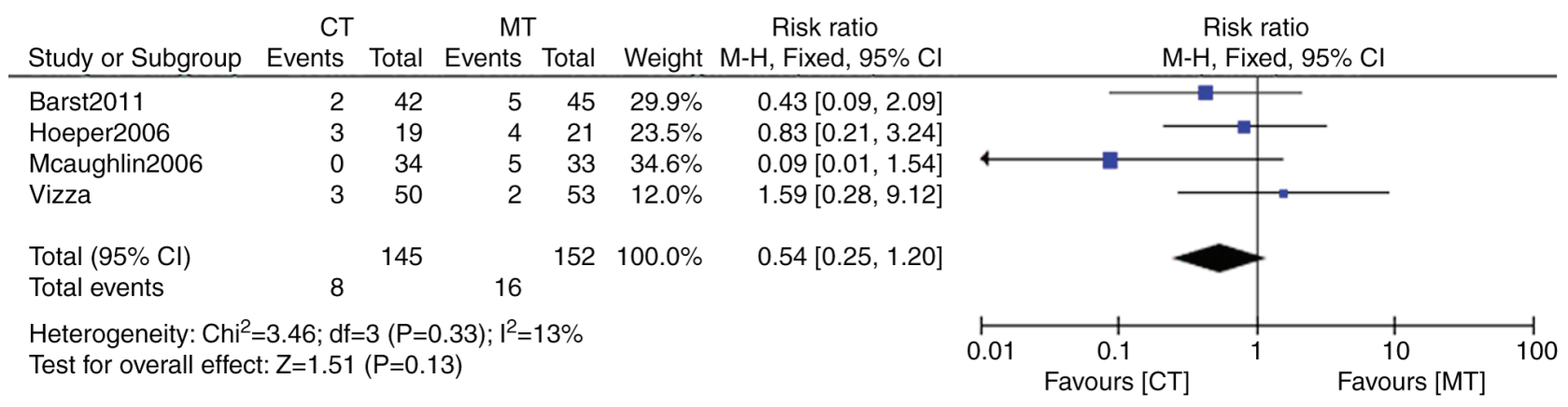

Figure 6. Effect of bosentan combined with prostacyclin analogues or phosphodiesterase type 5 inhibitors vs. bosentan monotherapy on clinical worsening. The heterogeneity between the groups was found to be non-significant. Clinical worsening incidence in the combination therapy was below that of monotherapy, but without statistical significance $(\mathrm{P}>0.05)$. CI, confidence intervals; CT, combination therapy; M-H, Mantel-Haenszel; MT, monotherapy.

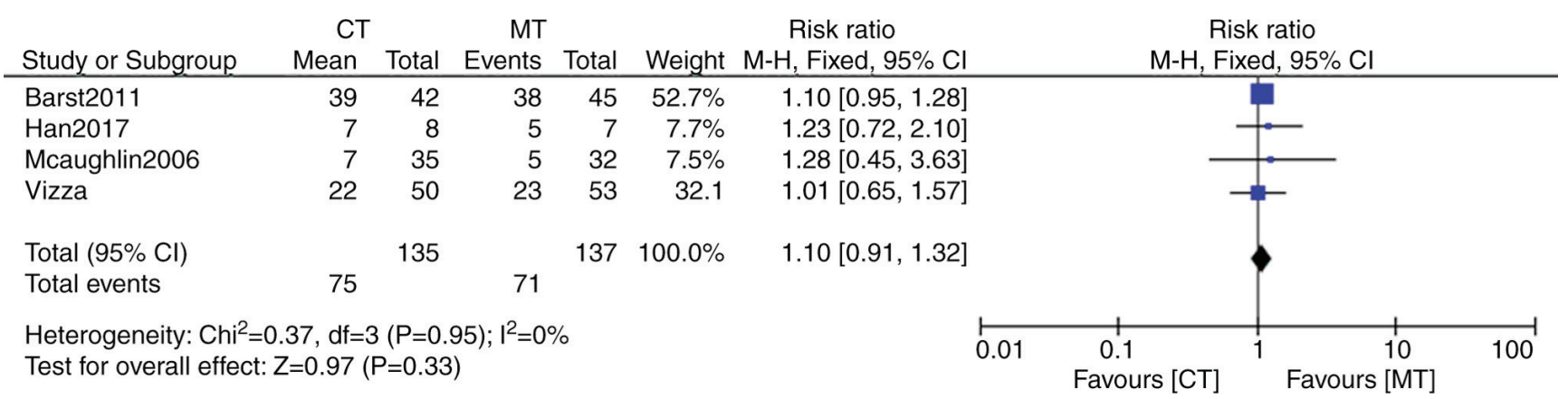

Figure 7. Effect of bosentan combined with prostacyclin analogues or phosphodiesterase type 5 inhibitors vs. bosentan monotherapy on adverse events. The incidence of adverse events was not significantly different between the bosentan combination therapy and the monotherapy groups (P>0.05). CI, confidence intervals; CT, combination therapy; M-H, Mantel-Haenszel; MT, monotherapy.

All of the five trials described adverse events, but in one study, detailed data on adverse events was not provided (23). These adverse events mainly included headaches, coughing, flushing, chest pains, nausea, dizziness and diarrhea. A total of 71 events $(51.8 \%$; $n=137)$ were reported in the monotherapy group, whereas 75 adverse events $(55.6 \%, \mathrm{n}=135)$ were reported in the combination therapy group (Fig. 7). The risk ratio of adverse events between combination and monotherapy was 1.1 (95\% CI: 0.91, 1.32). However, the difference between the groups was not statistically significant $(\mathrm{P}=0.33)$. Thus, the incidence of adverse events was not significantly different between the bosentan combination therapy and the monotherapy groups.

\section{Discussion}

For the present meta-analysis, rigorous selection criteria were applied. Studies of the bosentan treatment within 3 months prior to randomization, and studies in which the control group was treated with bosentan or placebo were included. These criteria resulted in only five studies that were included in this analysis, which comprised a total of 310 subjects. The present meta-analysis referred to the outcomes of previous studies of combination therapy, and also formed the basis on the safety and efficacy of combining bosentan with prostacyclin analogues or PDE-5 inhibitors.

The results from the present meta-analysis demonstrated that bosentan combined with prostacyclin analogues or PDE-5 inhibitors was superior to the bosentan monotherapy in reducing mPAP by $11.95 \mathrm{mmHg}$. However, compared with bosentan monotherapy, bosentan combined with prostacyclin analogues or PDE-5 inhibitors did not improve exercise capacity, cardiac function or clinical worsening in PAH. Notably $5.5 \%$ of the patients in the combination therapy developed clinical worsening compared with $10.5 \%$ in monotherapy. The clinical worsening rate was significantly 
reduced in the bosentan combination therapy group although the curative effect of treatment was not significant. These data indicated that although bosentan therapy relieved the patient of the symptoms and clinical worsening, it still failed to prevent and slow the progression of PAH. The incidence of adverse events in bosentan combination therapy was similar to that of monotherapy, which suggested that bosentan combination therapy was safe for PAH patients.

Drug interaction is a problem that cannot be ignored in combination drug therapies (37). Although the combination of bosentan with sildenafil or tadalafil could lead to a decrease in plasma concentration of sildenafil and tadalafil, bosentan concentration was increased by inducing cytochrome P450 3A4 isoenzyme. However, the clinical significance of this interaction has not been well established. Currently, there is no evidence that interactions between bosentan and sildenafil decrease drug safety.

Since the treatment regimens among the five studies were different, the effect of bosentan combination therapy could not be harmonized. In some studies, treatment with prostacyclin analogues or PDE-5 inhibitors was initiated prior to treatment with bosentan, whereas in other studies patients were treated with bosentan for some time and then given prostacyclin analogues or PDE-5 inhibitors (27-32). It was difficult to determine which combination therapy regimen was most effective, and current published guidelines do not offer a specific recommended regimen. As the current findings may be limited by the relatively short duration (12 weeks) of the trials, it was not possible to determine the long-term efficacy and safety of bosentan combination therapy. Therefore, the true clinical features and progression of the disease in patients could not be determined. Given the limited number of studies included in the present analysis, the results should be confirmed through future research. A larger randomized controlled trial should be designed for future studies to adequately assess the efficacy and safety of bosentan combination therapy.

In conclusion, results from the present meta-analysis suggested that bosentan combined with prostacyclin analogues or PDE-5 inhibitors do not impart additional advantages for the improvement of the 6MWD, cardiac function, clinical worsening, and incidence of adverse events. However, bosentan combined with prostacyclin analogues or PDE-5 inhibitors may significantly reduce mPAP compared with bosentan monotherapy.

\section{Acknowledgements}

Not applicable.

\section{Funding}

The present study was supported by The Natural Science Foundation of China under Grant (grant nos. 81660308 and 81460663).

\section{Availability of data and materials}

The datasets used and/or analysed during the current study are available from PubMed, Embase, the Cochrane Library and the www.clinicaltrials.gov website.

\section{Authors' contributions}

ZCD, ZQL and DXL contributed to study conception and design; drafted the submitted article, revised it critically for important intellectual content. ZCD and BL independently appraised study quality of the included trials and contributed to the analysis and interpretation of data. RLG contributed to study conception and design. ZCD and BT contributed to acquisition, analysis, and interpretation of data. ZCD and SL contributed to the literature search, acquisition of data, and drafted the manuscript. All authors read and approved the final manuscript.

\section{Ethics approval and consent to participate}

Not applicable.

\section{Patient consent for publication}

Not applicable.

\section{Competing interests}

The authors declare that they have no competing interests.

\section{References}

1. Peacock AJ, Murphy NF, Mcmurray JJ, Caballero L and Stewart S: An epidemiological study of pulmonary arterial hypertension. Eur Respir J 30: 104-109, 2007.

2. Humbert M, Morrell NW, Archer SL, Stenmark KR, MacLean MR, Lang IM, Christman BW, Weir EK, Eickelberg O, Voelkel NF and Rabinovitch M: Cellular and molecular pathobiology of pulmonary arterial hypertension. J Am Coll Cardiol 43 (12 Suppl S): 13S-24S, 2004.

3. Budhiraja R, Tuder RM and Hassoun PM: Endothelial dysfunction in pulmonary hypertension. Circulation 109: 159-165, 2004.

4. Humbert M, Sitbon O and Simonneau G: Treatment of pulmonary arterial hypertension. N Engl J Med 351: 1425-1436, 2004.

5. Badesch DB, Abman SH, Simonneau G, Rubin LJ and McLaughlin VV: Medical therapy for pulmonary arterial hypertension: Updated ACCP evidence-based clinical practice guidelines. Chest 131: 1917-1928, 2007.

6. Hoeper MM, Faulenbach C, Golpon H, Winkler J, Welte T and Niedermeyer J: Combination therapy with bosentan and sildenafil in idiopathic pulmonary arterial hypertension. Eur Respir J 24: 1007-1010, 2004

7. Seyfarth HJ, Pankau H, Hammerschmidt S, Schauer J, Wirtz H and Winkler J: Bosentan improves exercise tolerance and Tei index in patients with pulmonary hypertension and prostanoid therapy. Chest 128: 709-713, 2005.

8. Channick RN, Olschewski H, Seeger W, Staub T, Voswinckel R and Rubin LJ: Safety and efficacy of inhaled treprostinil as add-on therapy to bosentan in pulmonary arterial hypertension. J Am Coll Cardiol 48: 1433-1437, 2006.

9. Galie N, Manes A, Negro L, Palazzini M, Bacchi-Reggiani ML and Branzi A: A meta-analysis of randomized controlled trials in pulmonary arterial hypertension. Eur Heart J 30: 394-403, 2009.

10. Yang Z, Krasnici N and Lüscher TF: Endothelin-1 potentiates human smooth muscle cell growth to PDGF: Effects of ETA and ETB receptor blockade. Circulation 100: 5-8, 1999.

11. Price LC and Howard LS: Endothelin receptor antagonists for pulmonary arterial hypertension: Rationale and place in therapy. Am J Cardiovasc Drugs 8: 171-185, 2008.

12. McLaughlin VV, Shillington A and Rich S: Survival in primary pulmonary hypertension: The impact of epoprostenol therapy. Circulation 106: 1477-1482, 2002.

13. Barst RJ, Rubin LJ, McGoon MD, Caldwell EJ, Long WA and Levy PS: Survival in primary pulmonary hypertension with long-term continuous intravenous prostacyclin. Ann Intern Med 121: 409-415, 1994. 
14. Provencher S, Sitbon O, Humbert M, Cabrol S, Jaïs X and Simonneau G: Long-term outcome with first-line bosentan therapy in idiopathic pulmonary arterial hypertension. Eur Heart J 27: 589-595, 2006.

15. Sitbon O, Humbert M, Nunes H, Parent F, Garcia G, Hervé P, Rainisio M and Simonneau G: Long-term intravenous epoprostenol infusion in primary pulmonary hypertension: Prognostic factors and survival. J Am Coll Cardiol 40: 780-788, 2002.

16. Galie N, Humbert M, Vachiery JL, Gibbs S, Lang I, Torbicki A, Simonneau G, Peacock A, Vonk Noordegraaf A, Beghetti M, et al: 2015 ESC/ERS Guidelines for the diagnosis and treatment of pulmonary hypertension: The Joint Task Force for the Diagnosis and Treatment of Pulmonary Hypertension of the European Society of Cardiology (ESC) and the European Respiratory Society (ERS): Endorsed by: Association for European Paediatric and Congenital Cardiology (AEPC), International Society for Heart and Lung Transplantation (ISHLT). Eur Respir J 46: 903-975, 2015

17. Channick RN: Combination therapy in pulmonary arterial hypertension. Am J Cardiol 111 (8 Suppl): 16C-20C, 2013.

18. Haworth S and Rabinovitch M: Pulmonary circulation. In: Paediatric Cardiology. 3rd edition. Anderson RH, Baker EJ, Penny DJ, et al. Churchill Livingstone, Philadelphia, pp117-141, 2010.

19. Channick RN, Simonneau G, Sitbon O, Robbins IM, Frost A, Tapson VF, Badesch DB, Roux S, Rainisio M, Bodin F and Rubin LJ: Effects of the dual endothelin-receptor antagonist bosentan in patients with pulmonary hypertension: A randomised placebo-controlled study. Lancet 358: 1119-1123, 2001.

20. Rubin LJ, Badesch DB, Barst RJ, Galie N, Black CM, Keogh A, Pulido T, Frost A, Roux S, Leconte I, et al: Bosentan therapy for pulmonary arterial hypertension. N Engl J Med 346: 896-903, 2002.

21. Galiè N, Humbert M, Vachiery JL, Gibbs S, Lang I, Torbicki A, Simonneau G, Peacock A, Vonk Noordegraaf A, Beghetti M, et al: 2015 ESC/ERS Guidelines for the diagnosis and treatment of pulmonary hypertension. Kardiol Pol 73: 1127-1206, 2015 (In Polish).

22. Moher D, Pham B, Jones A, Cook DJ, Jadad AR, Moher M, Tugwell P and Klassen TP: Does quality of reports of randomised trials affect estimates of intervention efficacy reported in meta-analyses? Lancet 352: 609-613, 1998.

23. Barst RJ, Oudiz RJ, Beardsworth A, Brundage BH, Simonneau G, Ghofrani HA, Sundin DP and Galiè N; Pulmonary Arterial Hypertension and Response to Tadalafil (PHIRST) Study Group: Tadalafil monotherapy and as add-on to background bosentan in patients with pulmonary arterial hypertension. J Heart Lung Transplant 30: 632-643, 2011.

24. Galie N, Brundage BH, Ghofrani HA, Oudiz RJ, Simonneau G, Safdar Z, Shapiro S, White RJ, Chan M, Beardsworth A, et al: Tadalafil therapy for pulmonary arterial hypertension. Circulation 119: 2894-2903, 2009.

25. D'Alto M, Romeo E, Argiento P, Sarubbi B, Santoro G, Grimaldi N, Correra A, Scognamiglio G, Russo MG and Calabrò R: Bosentan-sildenafil association in patients with congenital heart disease-related pulmonary arterial hypertension and Eisenmenger physiology. Int J Cardiol 155: 378-382, 2012.

26. Iversen K, Jensen AS, Jensen TV, Vejlstrup NG and Sondergaard L: Combination therapy with bosentan and sildenafil in Eisenmenger syndrome: A randomized, placebo-controlled, double-blinded trial. Eur Heart J 31: 1124-1131, 2010.
27. McLaughlin VV, Benza RL, Rubin LJ, Channick RN, Voswinckel R, Tapson VF, Robbins IM, Olschewski H, Rubenfire M, Rubenfire M, et al: Addition of inhaled treprostinil to oral therapy for pulmonary arterial hypertension: A randomized controlled clinical trial. J Am Coll Cardiol 55: 1915-1922, 2010.

28. Tapson VF, Jing ZC, Xu KF, Pan L, Feldman J, Kiely DG, Kotlyar E, McSwain CS, Laliberte K, Arneson C, et al: Oral treprostinil for the treatment of pulmonary arterial hypertension in patients receiving background endothelin receptor antagonist and phosphodiesterase type 5 inhibitor therapy (the FREEDOM-C2 study): A randomized controlled trial. Chest 144: 952-958, 2013.

29. Sitbon O, Channick R, Chin KM, Frey A, Gaine S, Galiè N, Ghofrani HA, Hoeper MM, Lang IM, Preiss R, et al: Selexipag for the treatment of pulmonary arterial hypertension. N Engl J Med 373: 2522-2533, 2015.

30. Ghofrani HA, Galiè N, Grimminger F, Grünig E, Humbert M, Jing ZC, Keogh AM, Langleben D, Kilama MO, Fritsch A, et al: Riociguat for the treatment of pulmonary arterial hypertension. N Engl J Med 369: 330-340, 2013.

31. Tapson VF, Torres F, Kermeen F, Keogh AM, Allen RP, Frantz RP, Badesch DB, Frost AE, Shapiro SM, Laliberte K, et al: Oral treprostinil for the treatment of pulmonary arterial hypertension in patients on background endothelin receptor antagonist and/or phosphodiesterase type 5 inhibitor therapy (the FREEDOM-C study): A randomized controlled trial. Chest 142: 1383-1390, 2012.

32. Simonneau G, Torbicki A, Hoeper MM, Delcroix M, Karlócai K, Galiè N, Degano B, Bonderman D, Kurzyna M, Efficace M, et al: Selexipag: An oral, selective prostacyclin receptor agonist for the treatment of pulmonary arterial hypertension. Eur Respir J 40: 874-880, 2012

33. McLaughlin VV, Oudiz RJ, Frost A, Tapson VF, Murali S, Channick RN, Badesch DB, Barst RJ, Hsu HH and Rubin LJ: Randomized study of adding inhaled iloprost to existing bosentan in pulmonary arterial hypertension. Am J Respir Crit Care Med 174: 1257-1263, 2006.

34. Hoeper MM, Leuchte H, Halank M, Wilkens H, Meyer FJ, Seyfarth HJ, Wensel R, Ripken F, Bremer H, Kluge S, et al: Combining inhaled iloprost with bosentan in patients with idiopathic pulmonary arterial hypertension. Eur Respir J 28: 691-694, 2006.

35. Han X, Zhang Y, Dong L, Fang L, Chai Y, Niu M, Yu Y, Liu L, Yang X, Qu S and Li S: Treatment of pulmonary arterial hypertension using initial combination therapy of bosentan and iloprost. Respir Care 62: 489-496, 2017.

36. Vizza CD, Jansa P, Teal S, Dombi T and Zhou D: Sildenafil dosed concomitantly with bosentan for adult pulmonary arterial hypertension in a randomized controlled trial. BMC Cardiovasc Disord 17: 239, 2017.

37. Dingemanse J and van Giersbergen PL: Clinical pharmacology of bosentan, a dual endothelin receptor antagonist. Clin Pharmacokinet 43: 1089-1115, 2004.

This work is licensed under a Creative Commons Attribution-NonCommercial-NoDerivatives 4.0 International (CC BY-NC-ND 4.0) License. 